\title{
Using mobile robotic platforms to improve decision-making in geoscience field research
}

Cristina G. Wilson

Temple University

GSA Annual Meeting

September 2019 
Interdisciplinary Collaboration:

Geology, Robotics, \& Cognitive Psychology
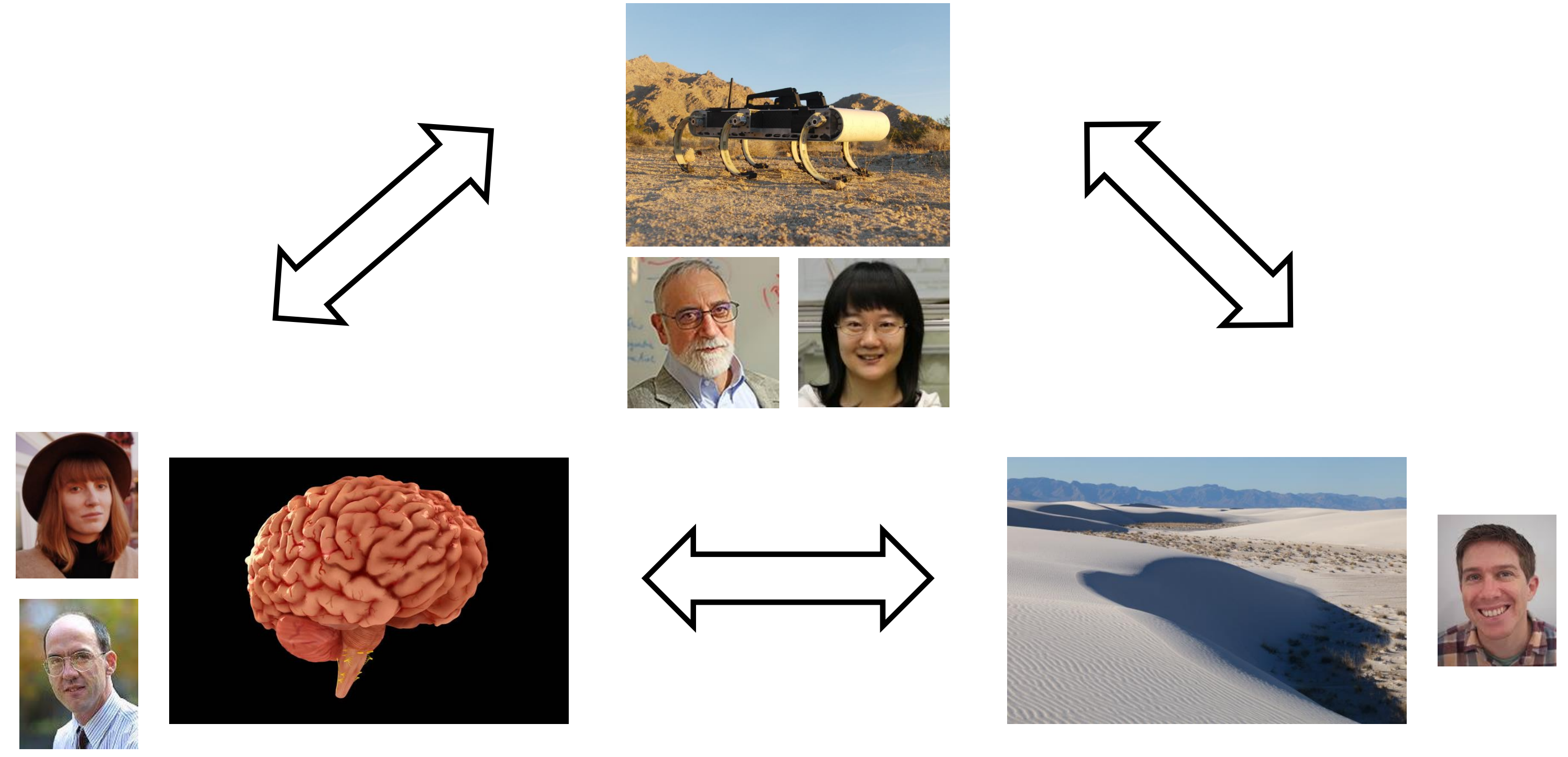

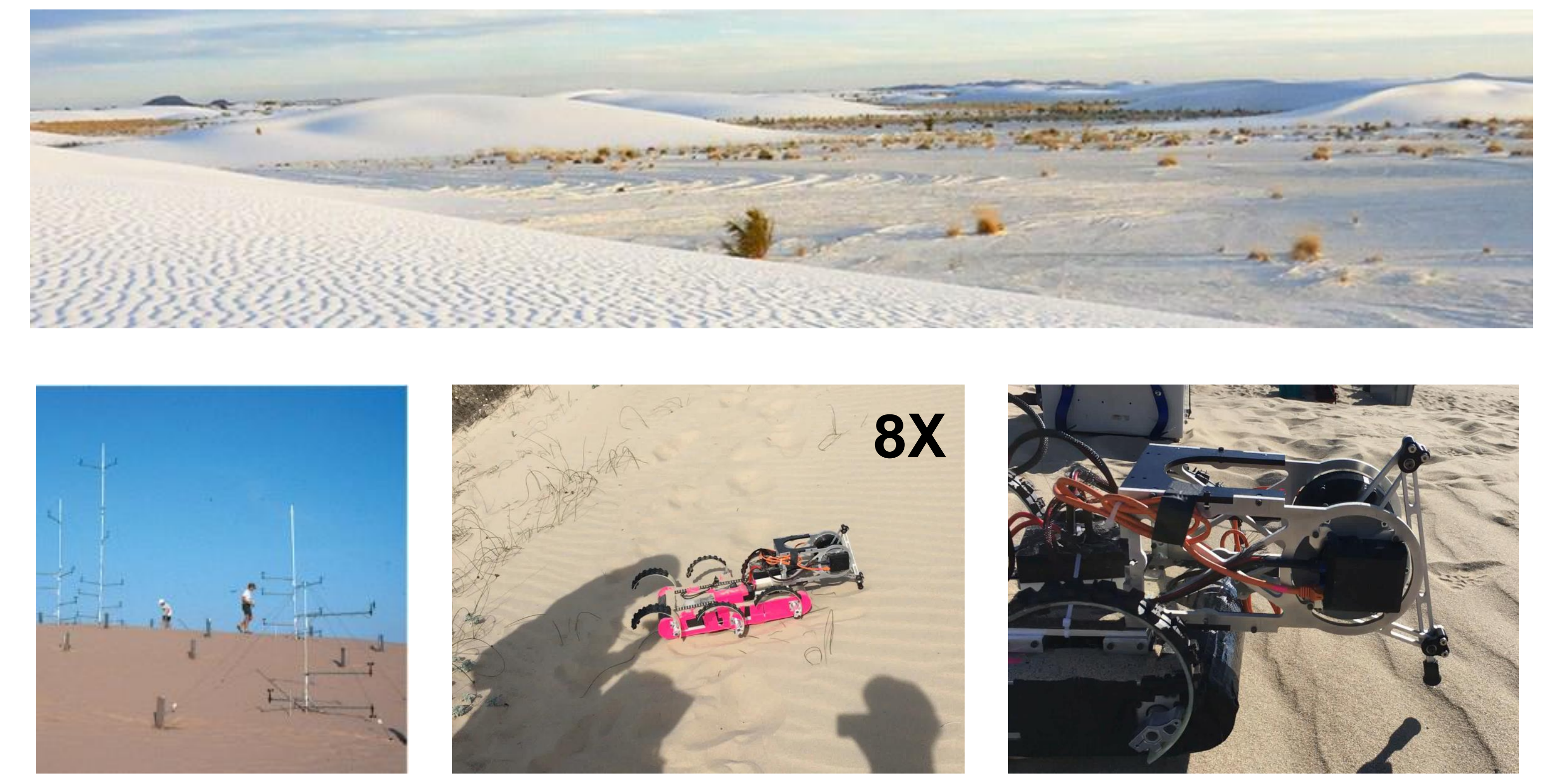

Qian et al. (2017) Aeolian Processes 


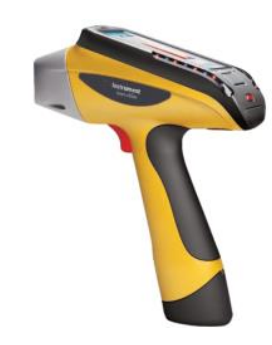
Wednesday
H. Hall AB, North No. 148
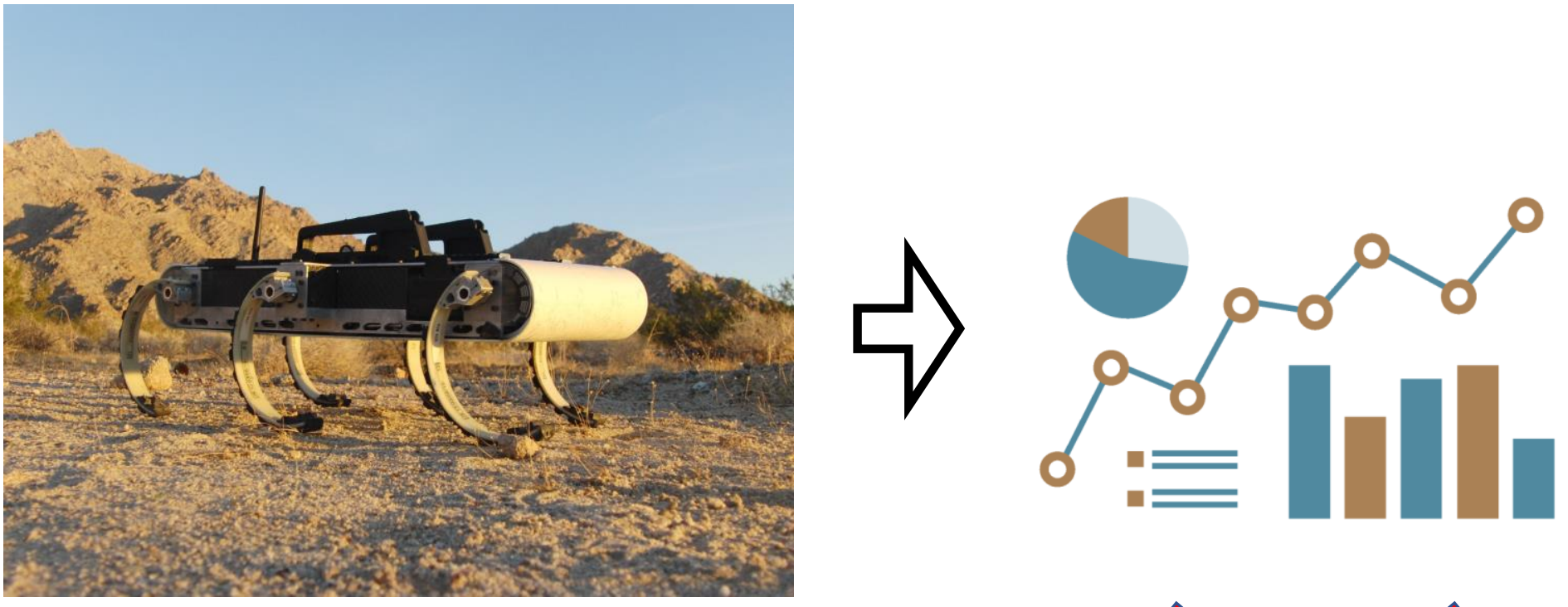

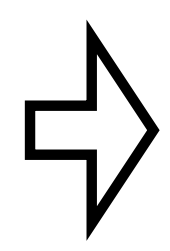

SSTRABOSPOT
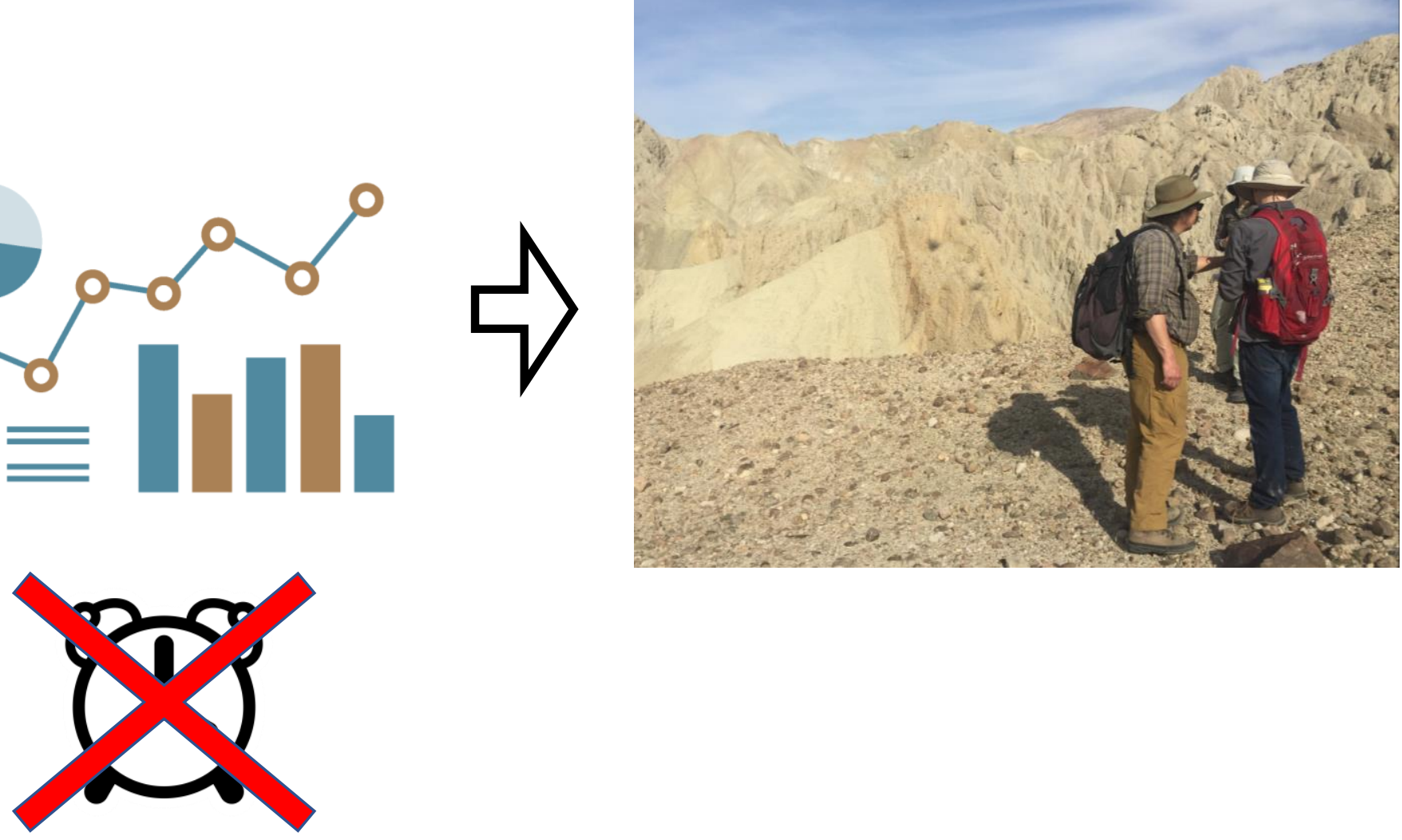


\section{How is geologic decision making influenced by the availability of real-time, in-situ measurement data?}




\section{Simulated Geologic Decision-Making Scenario}

Participants, $N=41$

- Geoscientists

- Recruited at AGU \& through research team contacts

- $73 \%$ male, $n=30$

- Roughly equal numbers of graduate students, postdocs, \& professors

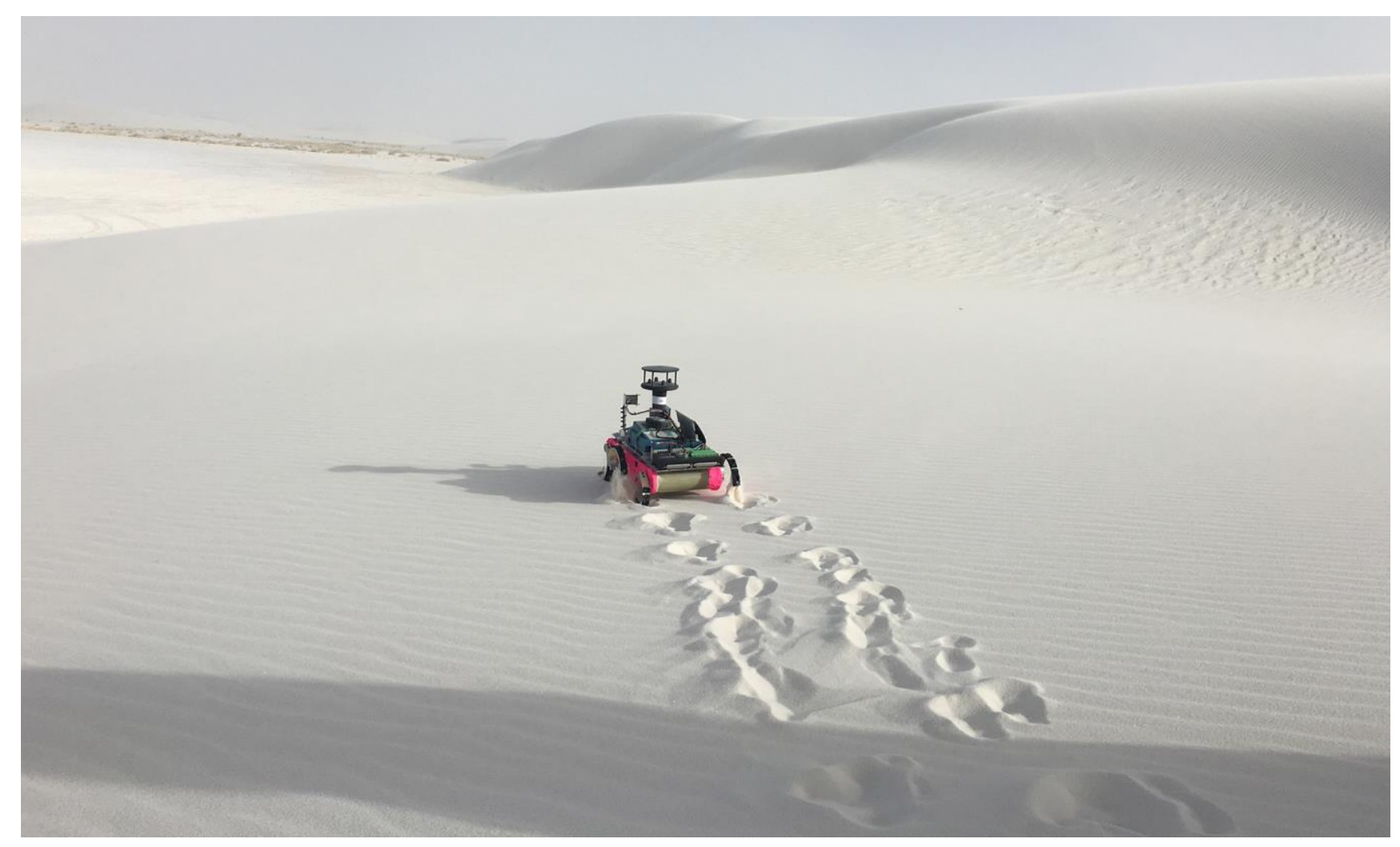


Soil Strength
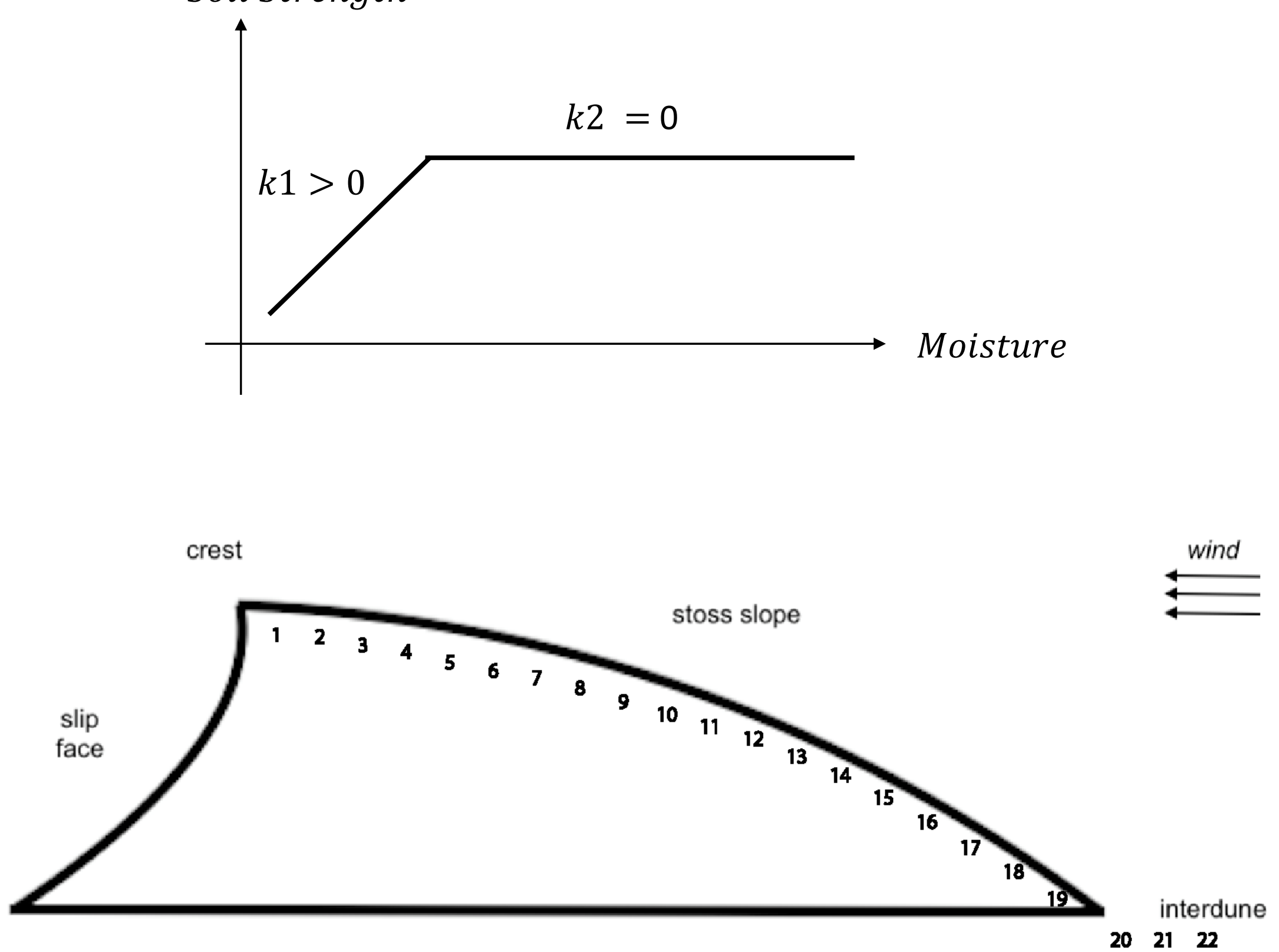


\section{Step 1. Select an Initial Sampling Strategy}

Total Number of Locations [up to 22]

Order to Visit Locations [no restrictions]

Number of Samples at Each Location [up to 10]

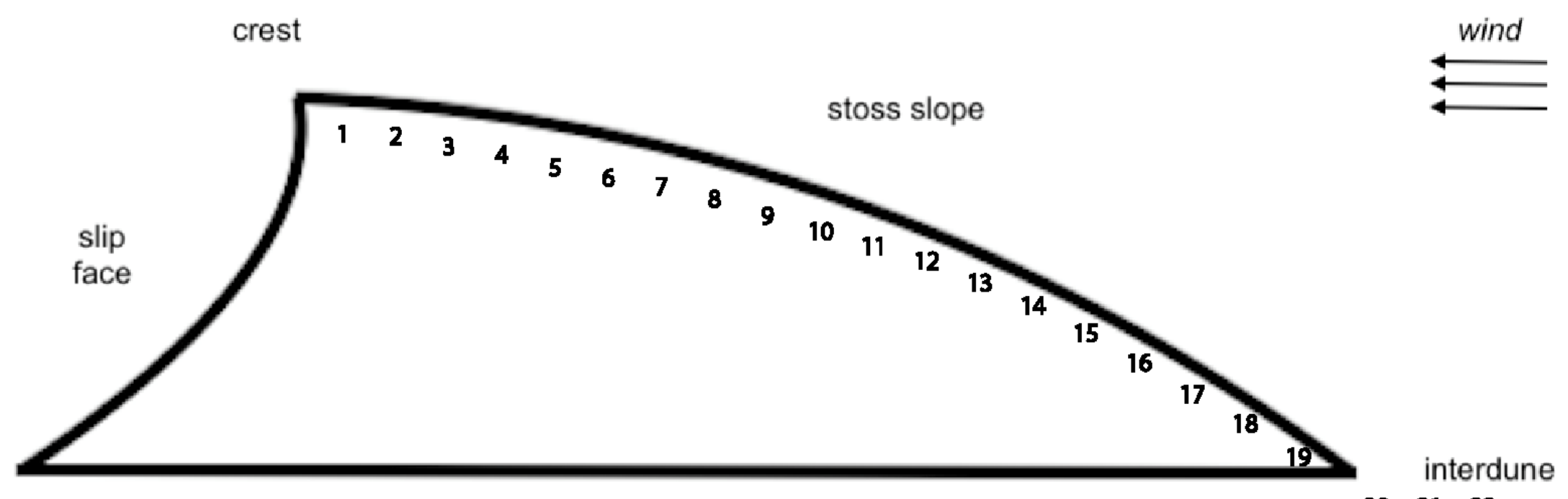




\section{Step 1. Select an Initial Sampling Strategy}

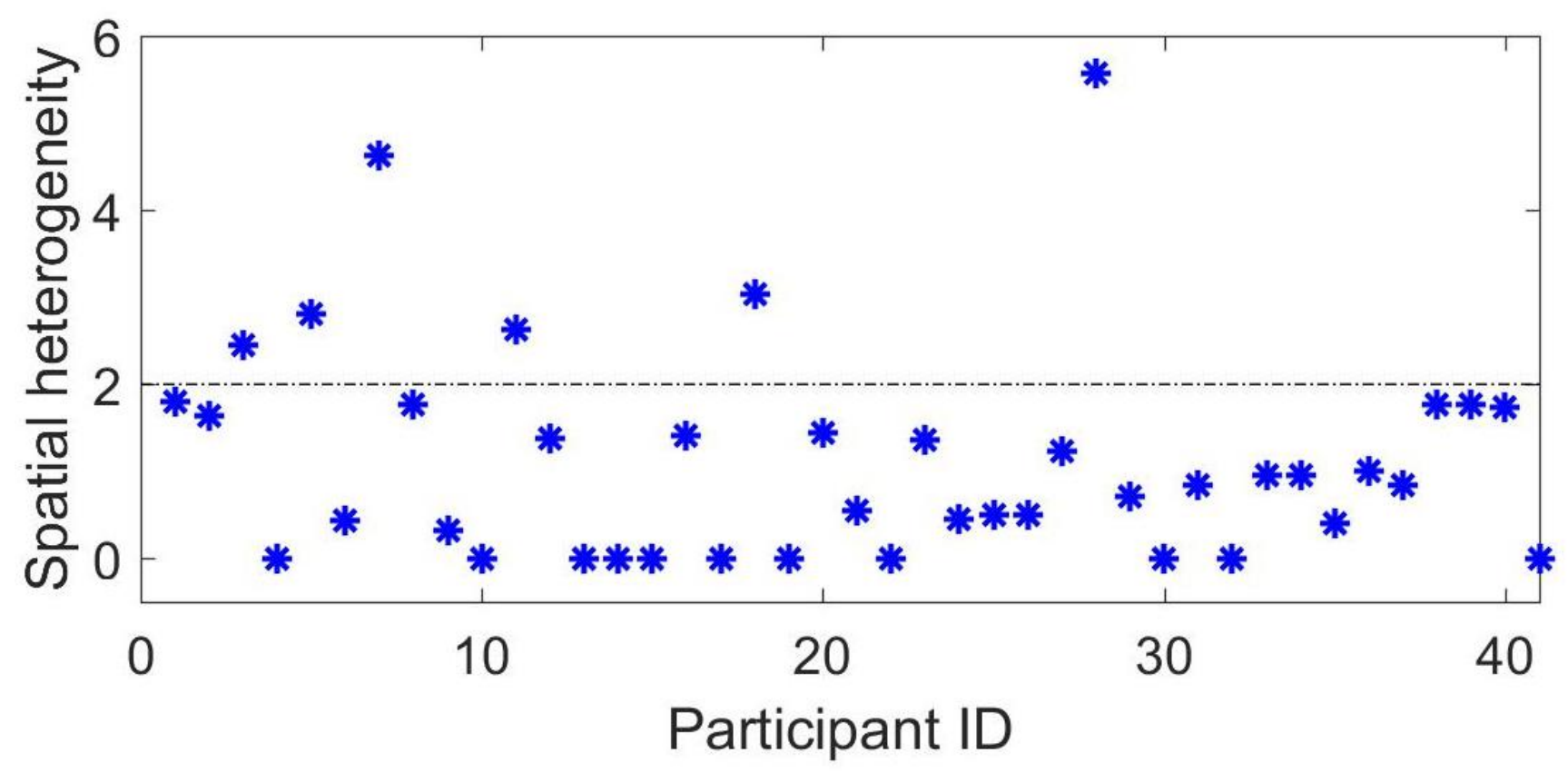

\section{$85 \%$ of participants}

chose locations at roughly homogenous intervals

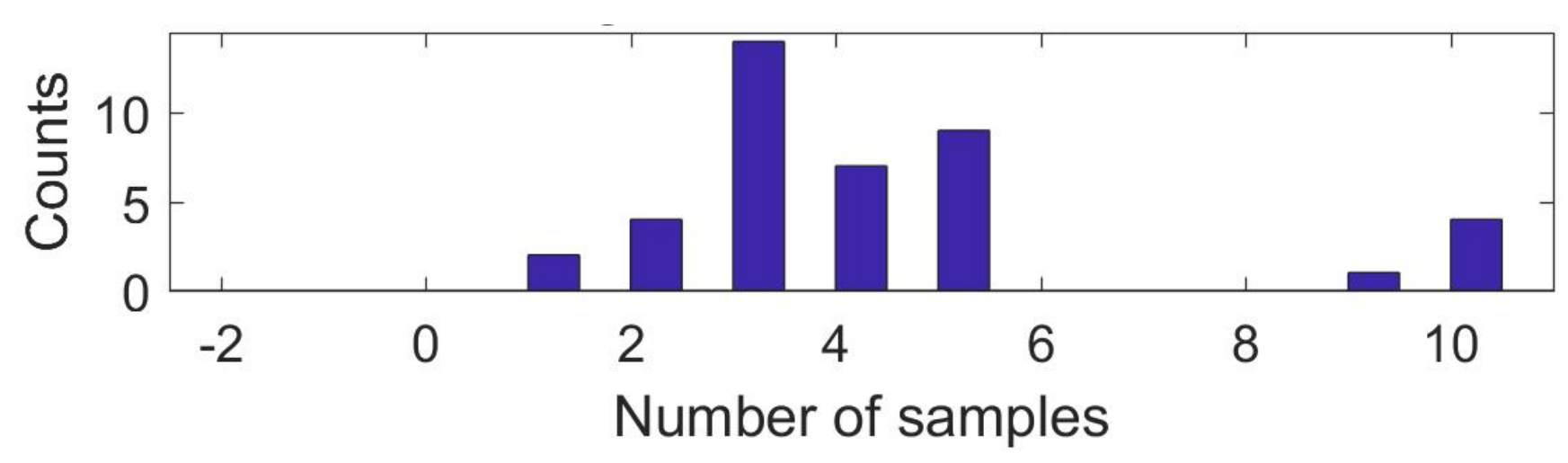

ALL participants took a consistent number of samples at each location, i.e., the MAGIC number 


\section{Step 2. Sampling Strategy is Executed and Data is Provided in Real-Time}

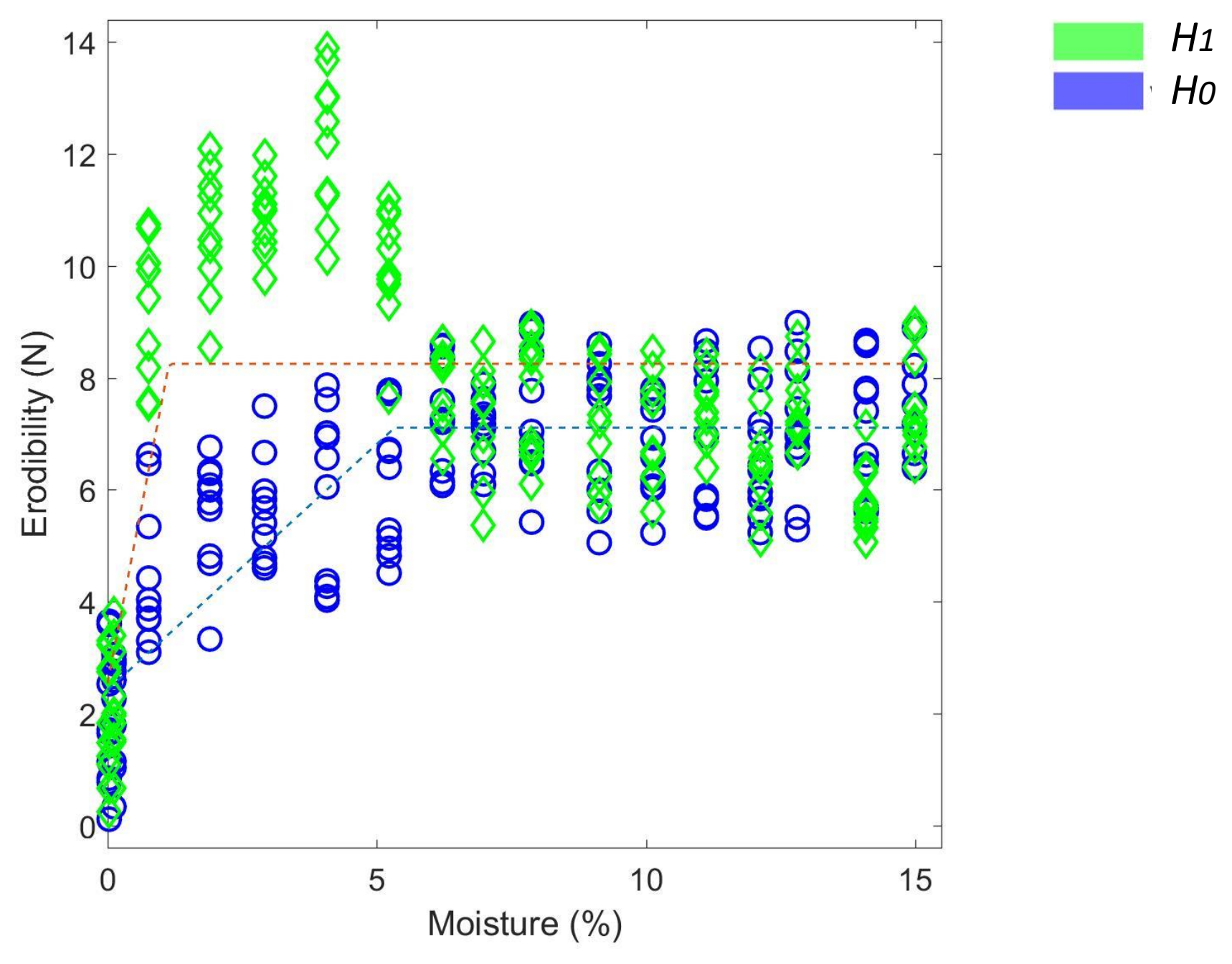



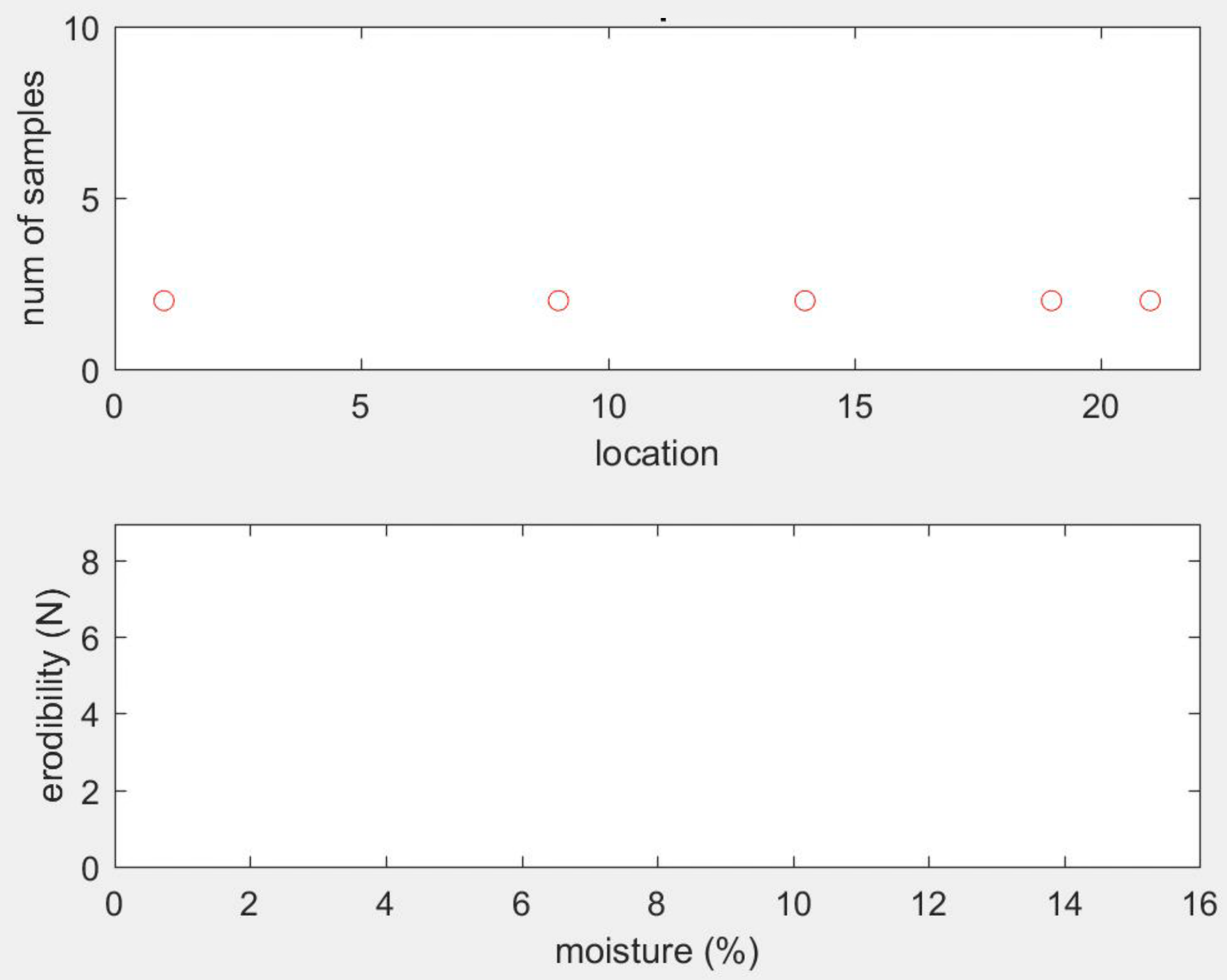


\section{Step 3. Changes in Sampling Strategy in Response to Incoming Data}

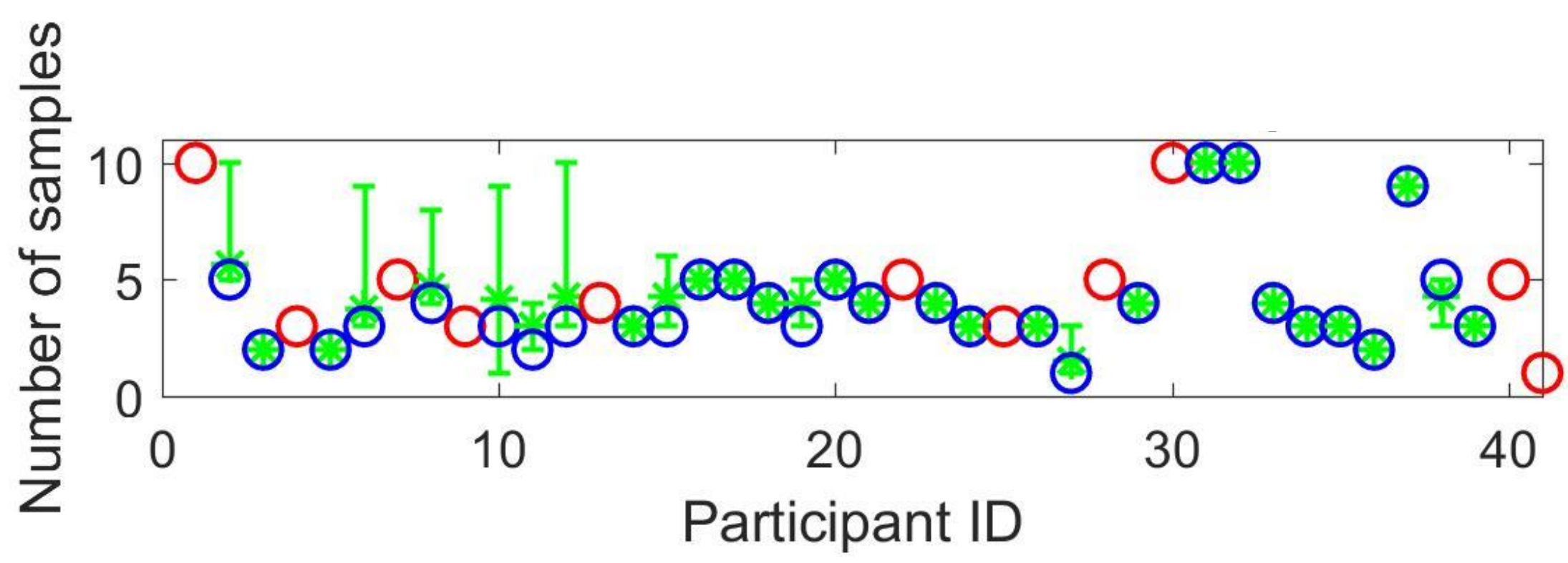

O- No change [27\%]

- 2 Change, same number [49\%]

$\odot$ Change, different number [24\%] 


\section{Conclusions}

\section{The Bad}

Anchoring bias

Initial sampling strategy

Magic number 


\section{Step 4. Make a Conclusion}

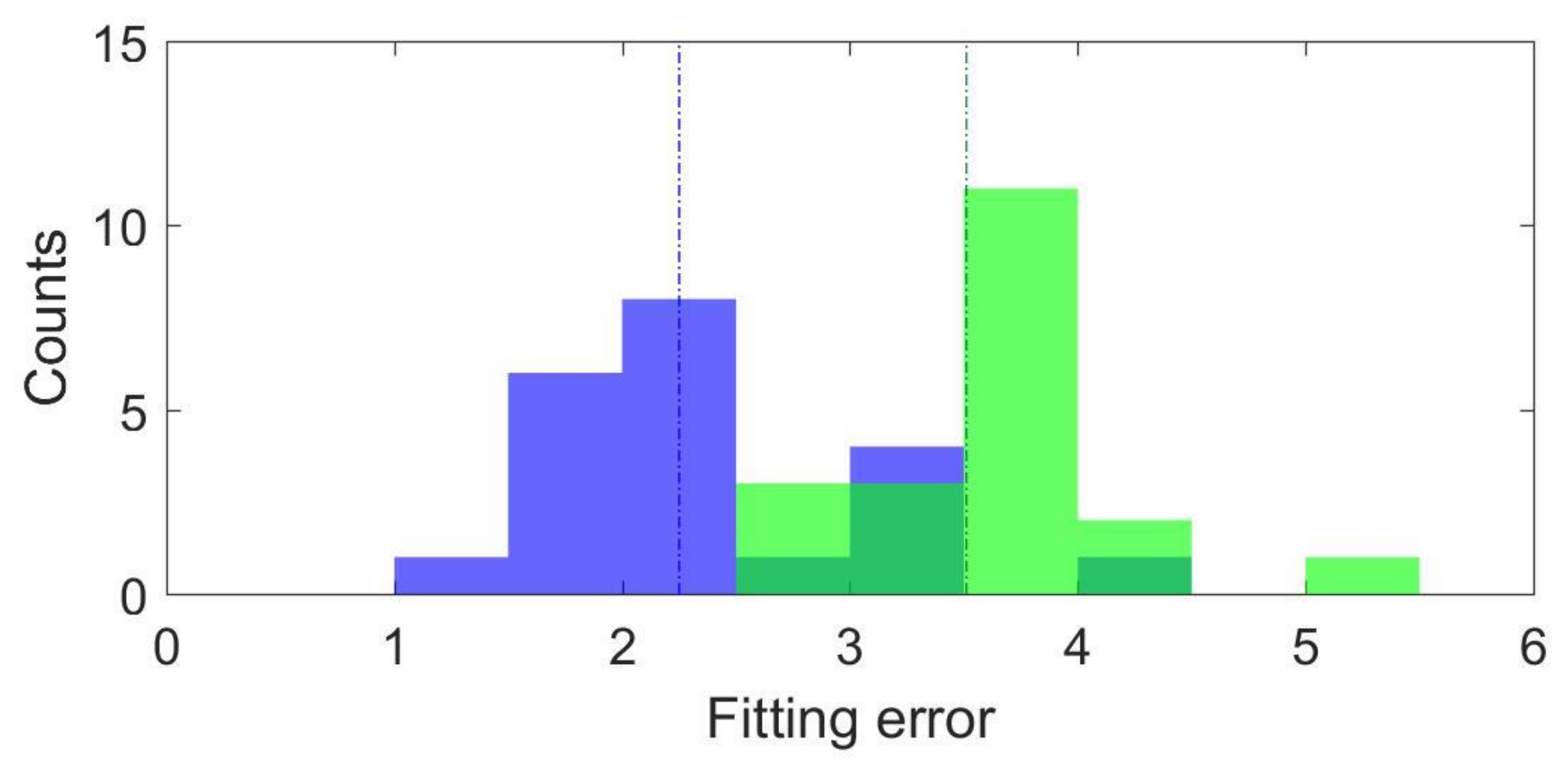

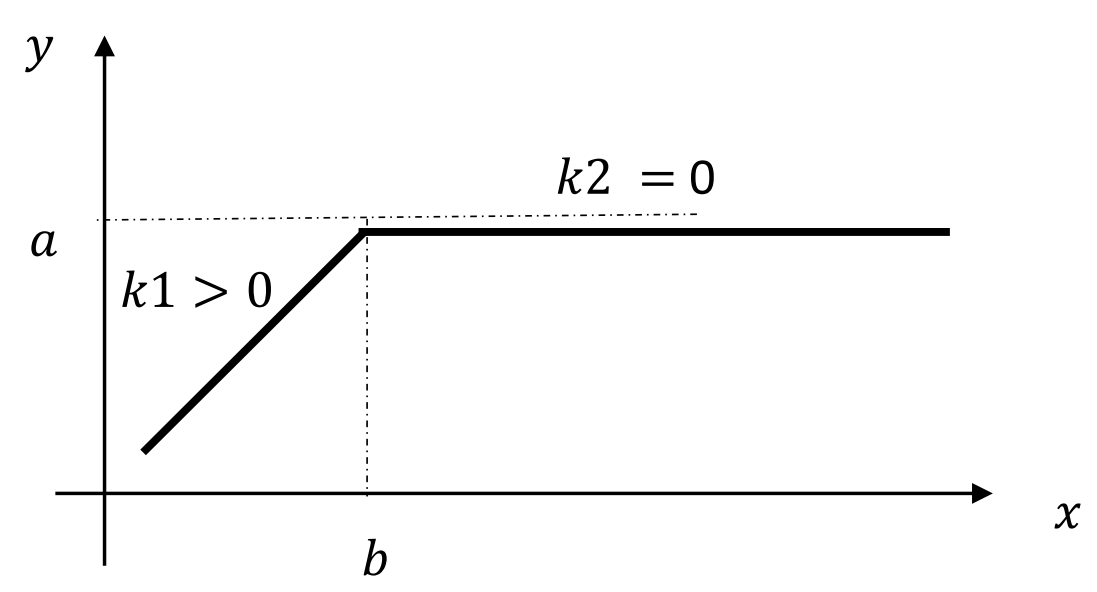

$H_{1}$
$H_{0}$

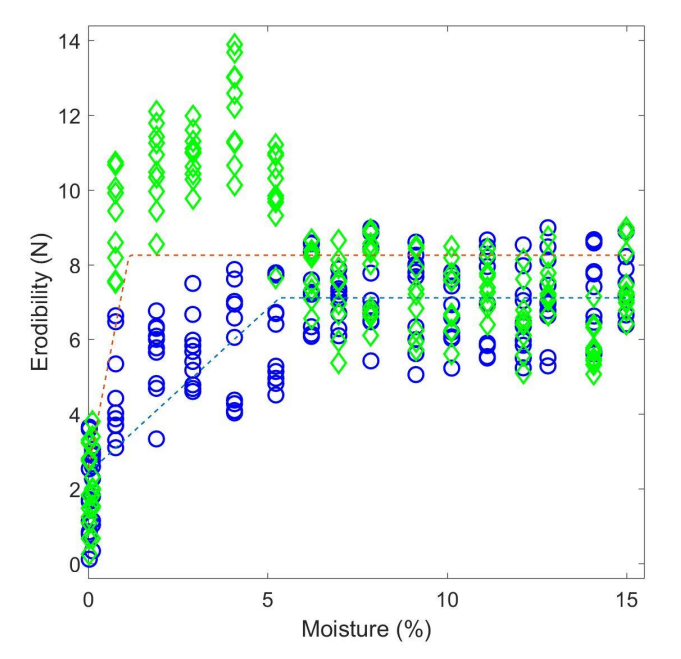




\section{Conclusions}

The Bad

Anchoring bias

Initial sampling strategy Magic number

\section{The Good}

Intuitive understanding of statistical fit

Simple step function 


\section{Thank You}

Collaborators:

- Feifei Qian

- Thomas Shipley

- Doug Jerolmack

- Dan Koditschek

- Sonia Roberts

Penn SeD:

- Rob Fetell

- Nakul Deshpande

- Kieran Dunne

RISC lab:

- Rebekah Banerjee

- Jon Ham
$K^{\prime} d^{*} l a b$ :

- Anmol Kathail

- Weiyi Tang

- Shivangi Misra

- Chun Chang

- Divya Ramesh

- Julia Messick

- Abriana Stewart-Height

- Shricharana Puthige

- Dan Guralnik

- Diedra Krieger

\section{TT TEMPLE}

College of Liberal Arts Department of Psychology
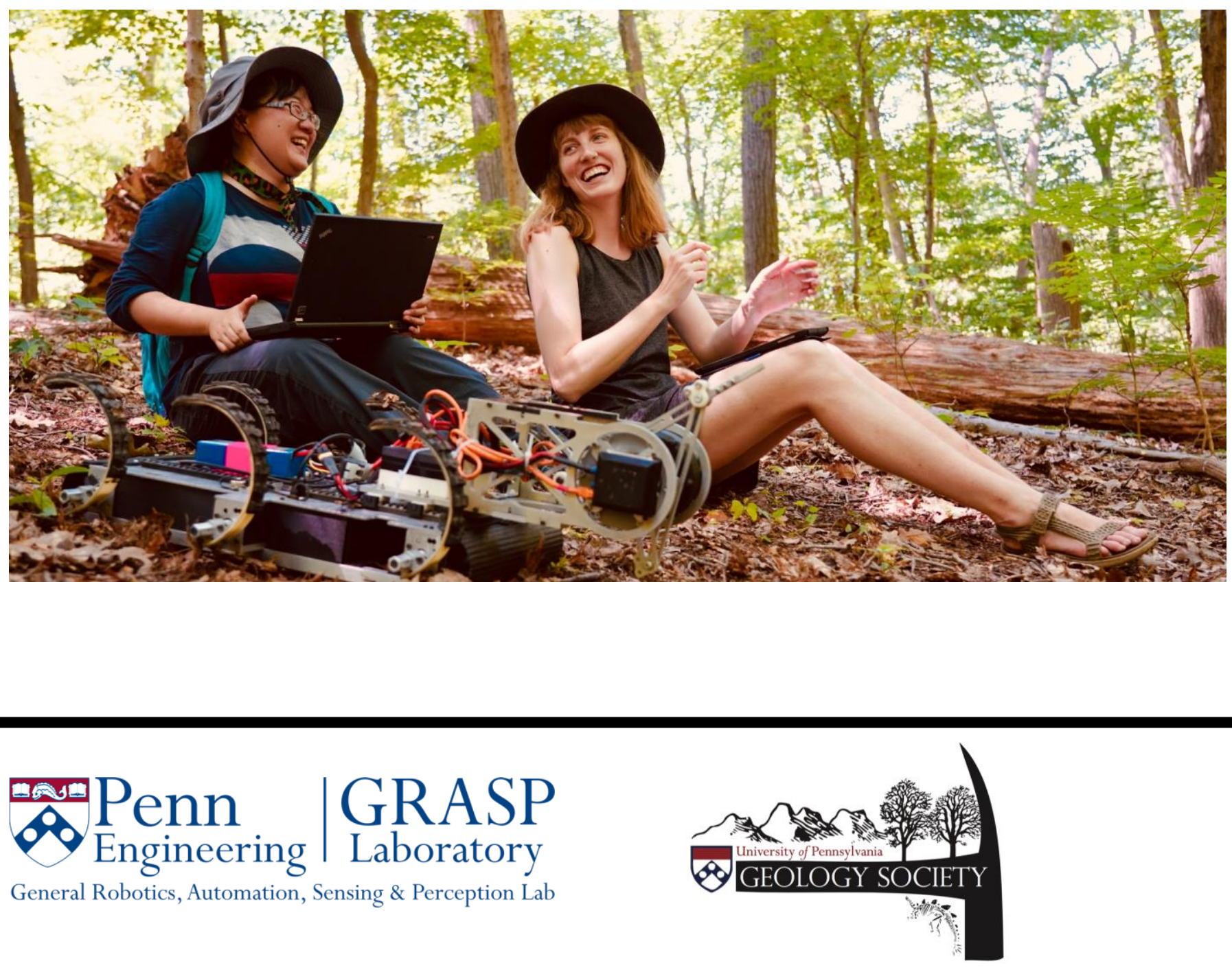